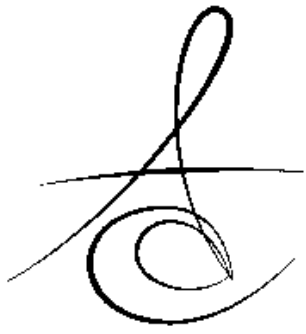

\title{
AĞIZ İÇİ TAMİR YÖNTEMLERİNİN RENK AÇISINDAN DEĞERLENDİRİLMESİ
}

EVALUATION OF INTRAORAL REPAIR METHODS IN TERMS OF COLOR

\author{
Dr. Öğr. Üyesi Emre TOKAR*
}

Doç. Dr. Serdar POLAT*

Makale Kodu/Article code: 3344

Makale Gönderilme tarihi: 01.02.2017

Kabul Tarihi; 07.06.2017

\section{öz}

Amaç: Çalışmamızın amacı iki farklı ağız içi porselen tamir seti (APTS) kullanılarak kompozit rezinle tamir edilen zirkonya restorasyonlarda dört farklı yüzey hazırlık yönteminin renge olan etkilerinin değerlendirilmesidir.

Gereç ve yöntem: Disk şeklinde $(2 \times 5 \mathrm{~mm}) 80$ adet zirkonya ve 80 adet zirkonya destekli porselen örnek hazırlanmıştır. Örneklerin L*a*b* değerleri kaydedilmiş ve iki farklı APTS (Clearfil Repair ve Ceramic Repair N) için porselen ve zirkonya örnekler ikiye ayrılmıştır. Bu ana gruplarda 40 örnek dört farklı yüzey hazırlık işleminin (elmas frezle pürüzlendirme, ağız içi kumlama, uzun ve kısa atım Er,Cr:YSGG lazer ışınlama) uygulanması için 4 alt gruba $(\mathrm{N}=$ 10) daha ayrımış̧ır. APTS'leri ve bu kitlerle uyumlu kompozit rezinler (Clearfil Majesty Esthetic ve Tetric N Ceram) örnek yüzeylerine tatbik edilmiştir. Kompozit rezinler her bir zirkonya ve porselen yüzeyine standart bir teflon kalıp $(2 \times 2$ $\mathrm{mm}$ ) kullanılarak inkremental teknikle yerleştirilmiştir. Tamir edilen örnek yüzeylerinde $L^{*} a * b *$ değerleri kaydedilmiş olup, ilgili formül kullanılarak $\Delta \mathrm{E}$ değerleri hesaplanmıştır. Başlangıৎ ve sonuç renk farklılıkları kaydedilip istatistiksel analiz (tek yönlü varyans analizi) yapılmıştır.

Bulgular: APTS ve yüzey hazırlık işlemlerine göre hesaplanan renk farklııkları klinik olarak kabul edilebilir değerden $(\Delta \mathrm{E}=5.5)$ yüksektir. Zirkonya destekli porselen örneklerde uzun atım lazer ışınlaması ve Clearfil Repair APTS uygulanan grup en düşük $\Delta \mathrm{E}$ değerini $(\Delta \mathrm{E}=5.90)$ göstermiştir. Kısa atım lazer ışınlaması ve Clearfil Repair APTS uygulandığı zirkonya örneklerin grubu diğer gruplara göre en yüksek renk değişikliğini $(\Delta \mathrm{E}=13.65)$ sergilemiştir.

Sonuç: Tamir edilen zirkonya ve zirkonya destekli porselenlerin ilk renklerine göre renk farklılıkları; tiplerine, kullanılan yüzey hazırlık yöntemlerine ve uygulanan APTS'lerine bağı olmaksızın klinik olarak kabul edilebilir değildir.

Anahtar kelimeler: Zirkonyum oksit, dental porselen, kompozit dental rezin, dental protez tamiri, renk, spektrofotometre.

\section{ABSTRACT}

Aim: The purpose of this study was to evaluate effect of four different surface treatment procedures on color alterations of zirconia restorations that was repaired with composite resin using two different intraoral porcelain repair systems.

Materials and method: 80 zirconia and 80 zirconia-based porcelain veneer were used to prepare disc-shaped specimens $(2 \times 5 \mathrm{~mm})$. L*a*b* values of specimens were recorded, and the zirconia and the porcelain specimens were divided into two main group for two different intraoral porcelain repair systems (Clearfil Repair ve Ceramic Repair $\mathrm{N}) .40$ specimens in that main groups were divided into four subgroup $(\mathrm{N}=10)$ in order to perform four different surface treatment procedures (surface grinding with diamond bur, intraoral sandblasting, long pulse and short pulse of $\mathrm{Er}, \mathrm{Cr}$ :YSGG laser irradiation). The intraoral porcelain repair kits and composite resins (Clearfil Majesty Esthetic Tetric N Ceram) that are compatible with the repair kits were applied to surface of the specimens. Composite resins were built-up on each zirconia and porcelain surfaces using a standard teflon mold $(2 \times 2 \mathrm{~mm})$ and incrementally filled. L*a*b* values of repaired specimens were recorded and $\Delta \mathrm{E}$ values were calculated using the formula. Color differences between the initial and final records were statistically analyzed (1-way ANOVA).

Results: The color changes which calculated upon surface treatments and intraoral porcelain repair kits were higher than clinical acceptability threshold $(\Delta \mathrm{E}=5.5)$. Zirconiabased porcelain specimens that were treated long pulse laser irradiation and repaired using Clearfil Repair intraoral porcelain repair kit group showed lowest $\Delta \mathrm{E}$ value $(\Delta \mathrm{E}=$ 5.90). Short pulse laser irradiation applied zirconia specimens that were repaired with Clearfil Repair kit group illustrated highest color changes $(\Delta \mathrm{E}=13.65)$ among the tested groups.

Conclusion: The color differences of repaired zirconia and zirconia-based porcelain veneer, regardless of their type, surface treatment method, and applied intraoral porcelain repair kit, was not clinically acceptable when compared to the initial shade of the specimens.

Keywords: Zirconium oxide, dental porcelain, composite dental resin, dental prosthesis repair, color, spectrophotometry.

* Gazi Üniversitesi Diş Hekimliği Fakültesi Protetik Diş Tedavisi Anabilim Dalı, 


\section{GİRİş}

Diş hekimliğinde sabit protetik tedavi yapımında metal destekli porselenler uzun süredir kullanılmaktadır. Restorasyonlarda alt yapı desteği olarak kullanılan metaller dayanıklılık sağlarken, porselen ise estetik kaliteyi arttırmaktadır. Porselenin altında metalin varlığı ve opak bir görüntüye sebep olması doğal diş renginin yansımasını engellemektedir. ${ }^{1}$

Metal alt yapının estetik dezavantajını ortadan kaldırmak için tam seramik restorasyonlar geliştirilmiştir. Tam seramik restorasyonların en büyük dezavantajları kolay kırılmaları ve düşük dayanıkılık dirençlerine sahip olmalarıdır. Tam seramikler basma kuvvetlerine dayanıklı oldukları halde gerilim kuvvetlerine karşı dayanıksızdırlar. ${ }^{2} \mathrm{Bu}$ bağlamda, zirkonya restorasyonlar estetik ve dayanıklılık özelliklerindeki üstünlükleri nedeniyle hekimler tarafından sıklıkla tercih edilmektedirler. Zirkonya kullanımı ile diğer tam seramiklere göre daha iyi kimyasal ve boyutsal kararlıık, mekanik başarı, gerilim direnci ve dayanıklılık elde edilmektedir. ${ }^{3}$

Zirkonya destekli porselen (ZDP) restorasyonlarda kullanılan zirkonya alt yapılar yeterli derecede dayanıkılığa sahiptirler, ancak üst yapı porselenindeki kırık ve çatlaklar sonucunda zirkonya alt yapının açığa çıkmasının insidansı hala yüksektir. ${ }^{4}$ Meydana gelen kırımalar ve alt yapının ortaya çıkması hala sorun oluşturabilmektedir., ${ }^{3}$ Buna karşın, zirkonya alt yapılar kırılmaya karşı dirençlidir fakat üst yapı porseleninde oluşan kırılmalar hala sorun oluşturabilmektedir. Uzun süreli klinik çalışmalar, ZDP restorasyonlarda en sık gözlemlenen başarısızlığın üst yapıdaki porselenin kırılması olduğunu göstermiştir. ${ }^{4}$ Zirkonya sinterleme prosedürleri ve yapısal defektler, ${ }^{5,6}$ kumlama işlemlerinin zirkoyumun dayanımını azaltması, ${ }^{7,8}$ altyapı tasarımı, ${ }^{9,10}$ kenar sonlanma şekli, ${ }^{11}$ tekrarlayan fırınlamalar, ${ }^{12-15}$ yapıştırma tekniği ${ }^{16,17}$ ve zirkoyumun yaşlanması $^{18,19}$ gibi faktörler zirkonya restorasyonlarında hasara sebep olabilir.

Restorasyonda oluşan kırık sonrasında ilk seçenek restorasyonu yenilemek ya da laboratuvarda restorasyonun tamirini yaptırmaktır. ${ }^{20} \mathrm{Bu}$ iki yöntem hem zaman alıcı hem de komplikasyona açıktır. Restorasyonun ağızdan çıkarılması durumunda hem restorasyonda hem de destek dişlerde daha büyük hasarlar meydana gelebilir. ${ }^{20,} 21 \mathrm{Bu}$ gibi durumların önüne geçmek için restorasyonu yerinden çıkartmadan kompozit reçine ile küçük defektlerin ağız içi tamiri tam seramik restorasyonlarda mümkün olabilmektedir. Günümüzde, ağız içi tamir sistemleri ile restorasyonların kullanım süreleri uzatılabilmekte, hasta ve hekim için hem maliyet hem de zaman açısından avantajlar elde edilebilmekte ve restorasyonu ağızdan çıkarırken restorasyonda ve destek dişlerde oluşabilecek muhtemel hasarlar önlenebilmektedir. ${ }^{21}$

Ağız içi porselen tamirinde kullanılan kompozit rezinler ile restorasyon arasındaki bağlantıyı güçlendirebilmek ve daha dayanıklı restorasyonlar elde etmek için restorasyon yüzeyinde çeşitli yüzey hazırlık işlemlerinin yapılması önerilmektedir. Üretici firmaların önerileri haricinde diğer yüzey hazırlık yöntemlerini araştıran çalışmalar da literatürde bulunmaktadır. Bu amaçla frezle pürüzlendirme, ağız içi kumlama, tribokimyasal silaka kaplama, asit uygulama, uzun ve kısa atım lazer uygulaması yapılmaktadır. ${ }^{21-27}$

Tamir edilen restorasyonların dayanıkılığı kadar estetiği de özellikle ön grup restorasyonlarda büyük önem arz etmektedir. Restorasyonun şekil ve formu hekimin becerisi ile yeniden sağlanabilmektedir, ancak renk uyumu her zaman elde edilememektedir. ${ }^{28}$ Veneer porselenin kalınlığı, ${ }^{29}$ fırınlama sayısı, ${ }^{14,} 15,30$ fırınlama parametreleri ve sıcaklıkları, ${ }^{29}$ kullanılan alt yapı materyali ${ }^{31-33}$ ve alt yapının yüzey hazırlığında kullanılan yöntemler ${ }^{28}$ bir seramik restorasyonun rengine etki eden faktörlerdir.

Ağız içi tamir yöntemleri ile kullanım süresi uzatılan restorasyonlarda yapılan uygulama sonrasında renk değiş̧iklikleri söz konusu olabilir. Çalışmamızın amacı iki farklı ağız içi porselen tamir seti (APTS) kullanılarak tamir edilen tam seramik restorasyonlarda yüzey hazırlık yöntemlerinin renge olan etkilerinin değerlendirilmesidir. $\mathrm{Bu}$ çalışmada öne sürülen hipotez; APTS ile tamir edilen tam zirkonya ve ZDP örneklerde renk farkılığı klinik olarak kabul edilebilir sınırlar içerisindedir.

\section{GEREÇ VE YÖNTEM}

Bu çalışmada, klinikte restorasyon kırıldığı zaman karşımıza çıkan 2 farklı durumu değerlendirmek amacıyla, disk şeklinde $5 \mathrm{~mm}$ çapında $2 \mathrm{~mm}$ yüksekliğinde 80 adet zirkonya (ICE Zirkon Translucent, Zirkonzahn GmbH, Gais, Almanya), 80 adet ZDP (Zirkonzahn GmbH / VITA VMK Master, Vita Zahnfabrik H. Rauter GmbH \& Co. KG, Bad Säckingen, 
Almanya) örnek hazırlanmışır. (Resim 1) ZDP örneklerde üretici firma önerileri doğrultusunda $1 \mathrm{~mm}$ kalınlı̆ı̆nda veneer porselen uygulanmıştır. Örneklerin hepsi Vita Easy Shade Guide (Vita Zahnfabrik H. Rauter GmbH \& Co. KG) renk skalasına göre A1 renginde hazırlanmışır. Hazırlanan toplam 160 adet örnek buhar makinesi ve ultrasonik temizleyici kullanılarak temizlenmiştir.

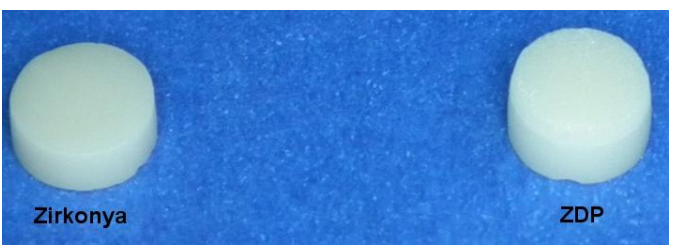

Resim 1. Hazırlanan zirkonya ve zirkonya destekli porselen (ZDP) örnekler.

Dijital spektrofotometre cihazı (Vita Easyshade Advance 4.0, Vita Zahnfabrik H. Rauter $\mathrm{GmbH} \&$ Co. KG) kullanılarak standart bir ortamda tüm örneklerin renk ölçümü yapılmıştır. Değerler CIE L*a*b* sistemine göre kaydedilmiştir.

Zirkonya ve ZDP örnekler 2 farklı APTS'nin uygulanması için iki ana gruba ayrılmıştır. 40 örnekli bu ana gruplar da 4 farklı yüzey pürüzlendirme işlemi için 4 alt gruba $(N=10)$ ayrılmıştır. Yapılan yüzey işlemleri ise şu şekildedir;

I- Kontrol

II- Ağız içi kumlama

III- Uzun atım lazer

IV- KIsa atım lazer

Kontrol gruplarında, örnek yüzeylerinde elmas frezle (FG 3053G, KG Sorensen, Cotia, SP, Brezilya) aşındırma yapılmıştır. Ağız içi kumlama işleminde, Rondo flex plus 360 ağız içi kumlama cihazı (KaVo Dental $\mathrm{GmbH}$, Biberach, Almanya) kullanılarak, $50 \mu \mathrm{m}$ boyutunda $\mathrm{Al}_{2} \mathrm{O}_{3}$ partiküller; $1 \mathrm{~mm}$ mesafeden 4 bar hava 1.5 bar su basıncı altında 20 saniye uygulanmıştır. Örneklerin yüzeylerini lazer ile pürüzlendirilmesinde, Er,Cr:YSGG (Erbium, Chromium: YttriumScandium-Gallium-Garnet) lazer (Millennium; Biolase Technology, Inc., San Clemente, CA, ABD) $2.78 \mu \mathrm{m}$ dalga boyunda kullanılmıştır. Fiber optik lazer (600 $\mu \mathrm{m}$ çapında, $6 \mathrm{~mm}$ uzunluğunda) örneklere $10 \mathrm{~mm}$ mesafeden uygulanmıştır. Uzun atım lazer grupları için $200 \mu \mathrm{s}$ ve kısa atım lazer grupları için $140 \mu \mathrm{s}, 20 \mathrm{~Hz}$ tekrarlama oranıyla uygulama yapılmıştır. İşlem esnasında \% 50 su ve \%50 hava püskürtülmüştür. Lazer uygulamaları 20 sn süreyle yapılmıştır.
Yüzey hazırlık işlemleri tamamlanan her alt grup ( $\mathrm{N}=10$ ) APTS'leri kullanılarak tamir işlemleri gerçekleştirilmiştir. Bunun için, Clearfil Repair (Kuraray Noritake Dental Inc, Okayama, Japonya) ve Ceramic Repair N (Ivoclar Vivadent AG, Schaan, Lihtenştayn) APTS'leri kullanılmıştır. Clearfil Repair tamir kitinin uygulandığı gruplarda üretici firmanın önermiş olduğu kompozit dolgu maddesi (Clearfil Majesty Esthetic, Kuraray Noritake Dental Inc) kullanılmıştır. Ceramic Repair $\mathrm{N}$ ile tamir edilen gruplarda da üreticinin önerdiği kompozit dolgu maddesi (Tetric N Ceram, Ivoclar Vivadent AG) uygulanmıştır.

Hazırlanan örneklerin yüzeylerine APTS uygulanmasında ve kompozit dolgu maddelerinin şekillendirilmesinde üretici firmaların belirtmiş olduğu işlem basamakları takip edilmiştir. APTS üreticilerinin önerdiği kompozit dolgu maddelerinin inkremental teknikle uygulanmasında $2 \times 2 \mathrm{~mm}$ boyutunda standart teflon kalıp kullanılmıştır. (Şekil 1)

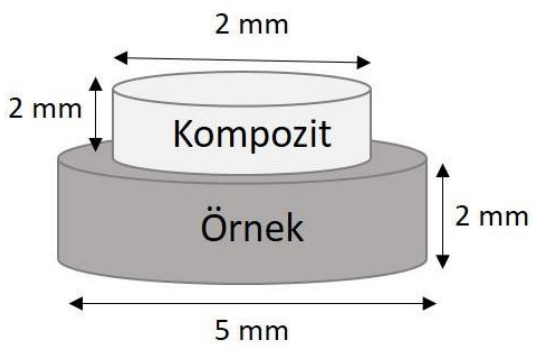

Şekil 1. Hazırlanan örnekler ve uygulanan kompozit reçinenin boyutları.

Kompozit rezin dolgu maddeleri ile tamir edilen örnek yüzeylerinin renk ölçümü standart bir ortamda dijital spektrofotometre cihazı ile CIE L*a*b* sistemine göre tekrar yapılmıştır ve kaydedilmiştir. Her bir örnek için başlangıç ve tamir sonrası L*a*b* değerleri bir tabloya yerleştirilmiş olup; $\Delta \mathrm{E}$ değerleri hesaplanmıştır. ${ }^{34}$

$\Delta \mathrm{E}_{(\mathrm{L}, \mathrm{a}, \mathrm{b})}=\left[\left(\mathrm{L}_{1}-\mathrm{L} *_{2}\right)^{2}+\left(\mathrm{a} *_{1}-\mathrm{a} *_{2}\right)^{2}+\left(\mathrm{b} *_{1}-\mathrm{b} *_{2}\right)^{2}\right]^{1 / 2}$

Grupların karşılaştırılmasında yapılan Shapiro wilk normallik analizi sonucunda $(p>0.05)$ ve varyans analizinin homojenlik testinde ( $p>0.05)$ grup dağılımlarının normal ve homojen olduğu saptandı. Yapılan bu testlerin sonuçları doğrultusunda parametrik test olan tek yönlü varyans analizi uygulandı. 


\section{BULGULAR}

Her bir yüzey grubu için elde edilen $\Delta \mathrm{E}$ değerleri Tablo $1^{\prime}$ de verilmiştir. $\Delta \mathrm{E}$ değeri $3.7^{\prime}$ nin üzerinde ise renkler arasındaki farklılık göz tarafından algılanabilir. $\Delta \mathrm{E}$ değeri 5.5 in üzerinde ise renk farklılı̆ı klinik olarak kabul edilemez seviyededir. ${ }^{35,} 36$

Çalışmanın sonuçlarına göre hem porselen hem de zirkonya yüzeylerde meydana gelen kırıklar porselenle aynı renkte bir kompozit dolgu maddesi ile restore edildiğinde gözle görülebilecek düzeyde renk değişiklikleri bulunmuştur. Yapılan çalışmada tüm örnek gruplarının $\Delta \mathrm{E}$ değerleri 5.5 in üstündedir. Yani tamir materyalleriyle yapılan restorasyon estetik açıdan istenilen seviyede değildir.

En düşük renk farklılı̆ı 5.90 değeri ile porselen örnek yüzeyinde uzun atım lazer yüzey hazırlığı sonrasında Clearfil Repair APTS'nin uygulandığı grupta bulunmuştur. Zirkonya örnek gruplarında kumlama ile yüzey hazırlığı sonrası Ceramic Repair N APTS ile yapılan uygulamada en düşük $\Delta E$ değeri (5.97) saptanmıştır. Tüm gruplar arasında en yüksek $\Delta \mathrm{E}$ değeri 13.65 ise zirkonya örnek yüzeyinde kısa atım lazer yüzey hazırlığı sonrasında yine Clearfil Repair APTS'nin uygulandığı grupta izlenmiştir.
Ağız içi porselen tamirinde kullanılan kompozit rezin ile restorasyon arasındaki bağlantıyı güçlendirebilmek için üretici firmaların önerileri haricinde çeşitli yüzey hazırlık yöntemlerini araştıran çalışmalar literatürde bulunmaktadır. Bu amaçla frezle pürüzlendirme, ağız içi kumlama, tribokimyasal silaka kaplama, asit uygulama, uzun ve kısa atım lazer uygulaması yapılmaktadır. ${ }^{21-27}$

Han ve arkadaşları ${ }^{27}$ zirkonya ile kompozit rezin arasındaki makaslama bağlantı dayanımını değerlendirdikleri çalışmalarında, tribokimyasal silika kaplama sağlayan CoJet sistemini uygulamanın kontrol grubuna göre bağlantı dayanımını istatistiksel olarak anlamlı derecede arttırdığını bildirmişlerdir. Kırmalı ve arkadaşları $^{21} 2015$ yılında yaptıkları bir çalışmada, YTZP seramik yüzeylerinde uygulanan tamir işlemlerinde çeşitli kumlama ve lazer uygulama prosedürlerinin bağlantı dayanımına etkisini araştırmışlardır. Zirkonya ve kompozit rezin arasındaki bağlantı dayanımını, kumlama ile birlikte uygulanan Nd:YAG lazer ışınlamanın ve tek başına uygulanan Er,Cr:YSGG lazer ışınlamanın istatistiksel olarak anlamlı derecede arttırdığı sonucuna ulaşmışlardır. Çalışmamızda da kullanılan APTS'lerini uygulamadan önce frezle pürüzlendirme, ağız içi kumlama ve Er, Cr:YSGG lazer uygulama (uzun ve kısa atım lazer) işlemleri ile yüzey hazırlıkları yapılmıştır.

Tablo 1. Zirkonya ve zirkonya destekli porselen (ZDP) örnek yüzeyleri için hesaplanan $\Delta \mathrm{E}$ değerlerinin tek yönlü varyans analizi.

\begin{tabular}{|c|c|c|c|c|c|c|c|c|c|c|c|c|}
\hline \multirow[b]{3}{*}{ Yüzey Hazırlığı } & \multicolumn{6}{|c|}{ Zirkonya } & \multicolumn{6}{|c|}{ ZDP } \\
\hline & \multicolumn{3}{|c|}{ Clearfil Repair } & \multicolumn{3}{|c|}{ Ceramic Repair N } & \multicolumn{3}{|c|}{ Clearfil Repair } & \multicolumn{3}{|c|}{ Ceramic Repair N } \\
\hline & $\Delta E$ & $\pm S . S$. & S. H. & $\Delta \mathrm{E}$ & $\pm S . S$. & S. H. & $\Delta \mathrm{E}$ & \pm S. S. & S. H. & $\Delta E$ & \pm S. S. & S. H. \\
\hline Kontrol & $6,85^{*}$ & 3,49 & 1,23 & $13,02^{\ddagger}$ & 1,58 & 0,65 & 7,09 & 3,16 & 1,12 & $10,63^{\ddagger}$ & 3,55 & 1,34 \\
\hline Kumlama & 7,29 & 2,77 & 0,98 & $5,97^{*}$ & 2,38 & 0,90 & 6,00 & 1,57 & 0,55 & $8,12^{*}$ & 0,96 & 0,36 \\
\hline Uzun lazer & 7,70 & 3,43 & 1,21 & 9,50 & 2,69 & 0,89 & $5,90^{*}$ & 0,93 & 0,33 & $8,15^{*}$ & 1,19 & 0,40 \\
\hline KIsa lazer & $13,65^{\ddagger}$ & 3,26 & 1,15 & 6,84 & 3,25 & 1,14 & $7,38^{\ddagger}$ & 0,71 & 0,25 & 9,77 & 2,01 & 0,71 \\
\hline
\end{tabular}

\section{TARTIŞMA}

Çalışmamızda öne sürülen hipotez elde edilen sonuçlar neticesinde kabul edilmemiştir. Hazırlanan tüm örnek grupları için, başlangıç ve tamir sonrası yapılan renk ölçümlerinde grupların $\Delta \mathrm{E}$ değerleri klinik olarak kabul edilebilir değer olan $5.5^{\prime} \mathrm{in}^{35}$, 36 üzerinde bulunmuştur.
Kırık seramik restorasyonların tamiri düşünüldüğünde genellikle tamir işlemi sonrası restorasyonun mekanik başarısı düşünülürken estetik başarısı ikinci plana itilmiştir. Oysa ki günümüz diş hekimliği pratiğinde, fonksiyonun başarısı kadar estetiğin sağlanması, restorasyonların doğal diş rengine uyumlu olması da büyük bir önem arz etmektedir. ${ }^{29} \mathrm{Bu}$ yüzden, 
zirkonya ve IPS Empress e-max gibi estetik materyaller kullanarak hazırlanan tam seramik restorasyonlara talep artmıştır. ${ }^{1-3} \mathrm{Bu}$ tip restorasyonlarda görülecek çatlak ve kırık neticesinde yapılacak tamir işlemlerinde estetik başarının da önemli olduğu yadsınamaz bir gerçektir.

Literatür incelendiğinde kullanılan alt yapı tasarımının ve yüzey hazırlığı yöntemlerinin porselen rengine olan etkilerini araştırmaların dikkate değer ölçüde çok olduğu gözlenmiştir. ${ }^{14,15, ~ 28, ~ 30-33 ~ F a k a t ~ a g ̆ ı z ~}$ içi porselen tamir işlemlerinin estetik başarıya etkisi ile ilgili detaylı bilgi bulunmamaktadır. Özcan ve Neidermier'in ${ }^{37}$ yaptıkları bir klinik çalışmada porselen kırıklarının büyük bir yüzdesinin üst çenede ve ön grup dişlerin labial yüzeyinde gözlendiği bildirilmiştir. Bu yüzden, porselen tamirinde estetik netice de son derece önemlidir. Zirkonya seramiklerde kırıma meydana geldiğinde seramik yüzey açığa çıkabilir ya da kırık zirkonya alt yapıya kadar uzanabilir. Yapılan bu çalışmamızda klinikte karşılaşılan bu iki durumda göz önüne alınarak iki farklı yüzey değerlendirilmiştir.

Doğal diş rengine uyumlu renkte restorasyon yapabilmek için renk seçimi ile birlikte rengi doğru tanımlayabilmek de önemlidir. Renk seçimi klinisyen için zor ve titizlikle yapılması gereken bir işlemdir. ${ }^{38}$ Dijital renk ölçüm cihazları görsel renk seçimine göre bazı avantajlara sahiptir. Dijital renk ölçümü daha objektif ve hızlıdır. Bunun yanında, tekrarlanabilir sayısal değer vermesi istatistiksel olarakta değerlendirilmesine olanak sağlar. ${ }^{38,39}$ Spektrofotometre cihazının güvenilirliğinin değerlendirildiği bir çalışmada, ölçüm tekrarlarında spektrofotometrede doğruluk payı \%83.3 olarak bulunmuştur. ${ }^{39}$ Çalışmamızda da spektrofotometre cihazı kullanılmış olup, değerlendirme kriterinin objektif olması sağlanmıştır.

Gonuldas ve arkadaşları ${ }^{14} 2014$ yılında yaptıkları bir çalışmada tekrarlayan fırınlamaların restorasyonların yüzey pürüzlülüğünü ve rengini etkilediği bildirilmişlerdir. Yazarlar, çoklu fırınlama işlemlerinden kaçınılmasını önermişlerdir. Yılmaz ve arkadaşları ${ }^{15}$ ise farklı cilalama tekniklerinin ve tekrarlayan fırınlamaIarın çeşitli tam seramik restorasyon materyallerinin rengine olan etkilerini araştırmışlardır. Tekrarlayan fırınlamaların porselen yüzeyinde ve kristalin yapıda yapısal değişikliklere neden olduğunu ve cilalama tekniğine bağlı olmaksızın restorasyon renginde de değişikliklere sebep olduğu sonucuna varmışlardır.
AlGhazali ve arkadaşlarının ${ }^{40}$ yapmış oldukları bir çalışmada dental porselenler ile porselen tamirinde kullanılan kompozit rezinlerin renk farklılıklarını değerlendirmişlerdir. Örneklerin $\Delta \mathrm{E}$ değerlerini 3.5 ile 26.9 arasında bulmuşlardır. Örneklerin neredeyse tamamına yakınının klinik olarak kabul edilebilir değerin $^{35,36}(\Delta \mathrm{E}=5.5)$ üzerinde olduğunu belirtip, ideal renk uyumu için tek renk kompozit rezin yerine renk kombinasyonlarının uygulanmasını önermişlerdir. Çalışmamızda da benzer şekilde $\Delta \mathrm{E}$ değerleri tüm gruplar için klinik olarak kabul edilebilir değer olan $5.5^{\prime}$ in $^{35,} 36$ üstündedir.

Bu çalışmada, asitle pürüzlendirme ve tribokimyasal silika kaplama gibi diğer yüzey hazırlık işlemlerinin değerlendirilmemesi ve renk skalasındaki tek bir rengin esas alınarak renk farklılıklarının karşılaştırılması çalışmanın sınırlamalarıdır.

Çalışmamızda değerlendirilen hem zirkonya hem de porselen örneklerde Ceramic Repair N APTS kullanılarak yapılan tamir işleminde restorasyonun esas rengi ile tamir sonrası renk arasındaki farklılığın diğer yüzey hazırlık işlemlerine göre daha yüksektir. Her iki örnek yüzeyinde Rondo Flex plus 360 ağız içi kumlama cihazı ile yapılan pürüzlendirmede renk farklılığının daha az olduğu görülmüştür.

Clearfil Repair ile tamir edilen zirkonya ve porselen örneklerde ise kısa atım lazer ile yapılan yüzey hazırlığı işlemi diğer yüzey hazırlığı işlemlerine göre daha yüksek $\Delta \mathrm{E}$ değerlerine neden olmuştur. Zirkonya alt yapının açığa çıktığı durumlarda Clearfil Repair APTS'nin önerdiği yüzey hazırlık işlemi olan elmas frezle pürüzlendirmenin, porselen yüzeylerde ise uzun atım lazer uygulaması ile yüzey hazırlığının yapılması tamir sonrası daha düşük renk farklılığına göstermiştir. Fakat hesaplanan $\Delta \mathrm{E}$ değerleri çalışmamızda kullanılan iki farklı APTS için de klinik olarak kabul edilebilir değerin ${ }^{35,36}$ üstündedir.

\section{SONUÇ}

ZDP restorasyonlarda kırık sonucunda açığa çıkan farklı yüzeylerde (zirkonya ve porselen) uygulanan dört değişik yüzey hazırlık işlemleri (frezle pürüzlendirme, ağız içi kumlama, uzun ve kısa atım lazer) sonrasında tatbik edilen iki farklı tamir setinin restorasyonla olan renk uyumunun değerlendirildiği çalışmamızın sonuçlarına göre tüm gruplarda $\Delta \mathrm{E}$ değeri klinik olarak kabul edilebilir değer olan 
$5.5^{\prime} \mathrm{in}^{35,36}$ üstünde çıkmıştır. Tamir edilen alan ile restorasyonun asıl rengi arasında arzu edilen renk uyumu elde edilememiştir. Estetiğin daha önemli olduğu durumlarda kırık ZDP restorasyonların kompozit rezinle tamiri yerine yenilenmesi de düşünülebilir.

\section{TEŞEKKÜRLER}

Bu çalışma Gazi Üniversitesi Bilimsel Araştırma Projeleri Birimi tarafindan desteklenmiştir. (Proje No: 03/201503)

Emre Tokar: ORCID ID: 0000-0003-2985-3499

Serdar Polat: ORCID ID: 0000-0003-0442-5789

\section{KAYNAKLAR}

1. Haselton DR, Diaz-Arnold AM, Hillis SL. Clinical assessment of high-strength all-ceramic crowns. J Prosthet Dent 2000;83:396-401.

2. Lawn BR, Deng Y, Lloyd IK, Janal MN, Rekow ED, Thompson VP. Materials design of ceramic-based layer structures for crowns. J Dent Res 2002;81:433-8.

3. Sailer I, Pjetursson BE, Zwahlen $\mathrm{M}$, Hammerle $\mathrm{CH}$. A systematic review of the survival and complication rates of all-ceramic and metalceramic reconstructions after an observation period of at least 3 years. Part II: Fixed dental prostheses. Clin Oral Implants Res 2007;18 Suppl 3:86-96.

4. Aboushelib MN, de Jager N, Kleverlaan CJ, Feilzer AJ. Microtensile bond strength of different components of core veneered all-ceramic restorations. Dent Mater 2005;21:984-91.

5. Monaco C, Tucci A, Esposito L, Scotti R. Microstructural changes produced by abrading $\mathrm{Y}$ TZP in presintered and sintered conditions. J Dent 2013;41:121-6.

6. Scherrer SS, Cattani-Lorente M, Vittecoq E, de Mestral F, Griggs JA, Wiskott HW. Fatigue behavior in water of Y-TZP zirconia ceramics after abrasion with 30 mum silica-coated alumina particles. Dent Mater 2011;27:e28-42.

7. Cattani Lorente M, Scherrer SS, Richard J, Demellayer R, Amez-Droz M, Wiskott HW. Surface roughness and EDS characterization of a Y-TZP dental ceramic treated with the CoJet Sand. Dent Mater 2010;26:1035-42.
8. Fischer J, Grohmann P, Stawarczyk B. Effect of zirconia surface treatments on the shear strength of zirconia/veneering ceramic composites. Dent Mater J 2008;27:448-54.

9. Kokubo Y, Tsumita M, Kano T, Fukushima S. The influence of zirconia coping designs on the fracture load of all-ceramic molar crowns. Dent Mater J 2011;30:281-5.

10. Sornsuwan T, Swain MV. Influence of occlusal geometry on ceramic crown fracture; role of cusp angle and fissure radius. J Mech Behav Biomed Mater 2011;4:1057-66.

11. Comlekoglu M, Dundar M, Ozcan M, Gungor M, Gokce $B$, Artunc $C$. Influence of cervical finish line type on the marginal adaptation of zirconia ceramic crowns. Oper Dent 2009;34:586-92.

12. Subasi MG, Demir N, Kara O, Ozturk AN, Ozel F. Mechanical properties of zirconia after different surface treatments and repeated firings. J Adv Prosthodont 2014;6:462-7.

13. Vichi A, Sedda M, Bonadeo G, Bosco M, Barbiera A, Tsintsadze $\mathrm{N}$ et al. Effect of repeated firings on flexural strength of veneered zirconia. Dent Mater 2015;31:e151-6.

14. Gonuldas F, Yilmaz K, Ozturk C. The effect of repeated firings on the color change and surface roughness of dental ceramics. J Adv Prosthodont 2014;6:309-16.

15. Yilmaz K, Gonuldas F, Ozturk C. The effect of repeated firings on the color change of dental ceramics using different glazing methods. J Adv Prosthodont 2014;6:427-33.

16. Son $\mathrm{YH}$, Han $\mathrm{CH}$, Kim S. Influence of internal-gap width and cement type on the retentive force of zirconia copings in pullout testing. J Dent 2012;40:866-72.

17. Inokoshi M, Kameyama A, De Munck J, Minakuchi $S$, Van Meerbeek B. Durable bonding to mechanically and/or chemically pre-treated dental zirconia. J Dent 2013;41:170-9.

18. Lughi V, Sergo V. Low temperature degradation aging- of zirconia: A critical review of the relevant aspects in dentistry. Dent Mater 2010;26:807-20.

19. Tang X, Tan Z, Nakamura T, Yatani H. Effects of ageing on surface textures of veneering ceramics for zirconia frameworks. J Dent 2012;40:913-20.

20. Cristoforides P, Amaral R, May LG, Bottino MA, Valandro LF. Composite resin to yttria stabilized

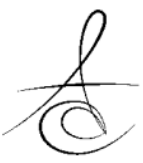


tetragonal zirconia polycrystal bonding: comparison of repair methods. Oper Dent 2012;37:263-71.

21. Oh WS, Shen C. Effect of surface topography on the bond strength of a composite to three different types of ceramic. J Prosthet Dent 2003;90:241-6.

22. Kirmali O, Barutcigil C, Ozarslan MM, Barutcigil K, Harorli OT. Repair bond strength of composite resin to sandblasted and laser irradiated Y-TZP ceramic surfaces. Scanning 2015;37:186-92.

23. Kirmali O, Kapdan A, Harorli OT, Barutcugil C, Ozarslan MM. Efficacy of ceramic repair material on the bond strength of composite resin to zirconia ceramic. Acta Odontol Scand 2015;73:28-32.

24. Yoo JY, Yoon HI, Park JM, Park EJ. Porcelain repair-influence of different systems and surface treatments on resin bond strength. J Adv Prosthodont 2015;7:343-8.

25. Duzyol M, Sagsoz O, Polat Sagsoz N, Akgul N, Yildiz $M$. The effect of surface treatments on the bond strength between CAD/CAM blocks and composite resin. J Prosthodont 2016;25:466-71.

26. Capa N, Ozkurt Z, Kazazoglu E. Ağız içi porselen tamir sistemleri. J Dent Fac Atatürk Uni 2006;16:34-40.

27. Han IH, Kang DW, Chung $\mathrm{CH}$, Choe $\mathrm{HC}$, Son MK. Effect of various intraoral repair systems on the shear bond strength of composite resin to zirconia. J Adv Prosthodont 2013;5:248-55.

28. Ozcelik TB, Yilmaz B, Ozcan I, Wee AG. Color change during the surface preparation stages of metal ceramic alloys. J Prosthet Dent 2011;106:3847.

29. Barghi N, Richardson JT. A study of various factors influencing shade of bonded porcelain. J Prosthet Dent 1978;39:282-4.

30. Yilmaz B, Ozcelik TB, Wee AG. Effect of repeated firings on the color of opaque porcelain applied on different dental alloys. J Prosthet Dent 2009;101:395-404.

31. Crispin BJ, Okamoto SK, Globe H. Effect of porcelain crown substructures on visually perceivable value. J Prosthet Dent 1991;66:20912.

32. Crispin BJ, Seghi RR, Globe H. Effect of different metal ceramic alloys on the color of opaque and dentin porcelain. J Prosthet Dent 1991;65:351-6.

33. Ozcelik TB, Yilmaz B, Ozcan I, Kircelli C.
Colorimetric analysis of opaque porcelain fired to different base metal alloys used in metal ceramic restorations. J Prosthet Dent 2008;99:193-202.

34. Paravina RD, Powers JM. Esthetic color training in dentistry. 1st ed. St. Louis: Elsevier; 2004, p.192.

35. Douglas RD, Steinhauer TJ, Wee AG. Intraoral determination of the tolerance of dentists for perceptibility and acceptability of shade mismatch. J Prosthet Dent 2007;97:200-8.

36. Johnston WM, Kao EC. Assessment of appearance match by visual observation and clinical colorimetry. J Dent Res 1989;68:819-22.

37. Ozcan M, Niedermeier W. Clinical study on the reasons for and location of failures of metalceramic restorations and survival of repairs. Int J Prosthodont 2002;15:299-302.

38. Okubo SR, Kanawati A, Richards MW, Childress S. Evaluation of visual and instrument shade matching. J Prosthet Dent 1998;80:642-8.

39. Paul S, Peter A, Pietrobon N, Hammerle $\mathrm{CH}$. Visual and spectrophotometric shade analysis of human teeth. J Dent Res 2002;81:578-82.

40. AlGhazali N, Jarad FD, Smith PW, Preston AJ. Colour match between porcelain and porcelainrepairing resin composites. Eur J Prosthodont Restor Dent 2012;20:3-9.

\section{Yazışma Adresi}

Dr. Öğr. Üyesi Emre TOKAR

Gazi Üniversitesi Diş Hekimliği Fakültesi

Emek Mah. Bişkek Cd. (8. Cd.) 1. Sk. No:4

06490 Çankaya-ANKARA

Email: emretokar@yahoo.com

Tel: +90 3122034192 